\title{
GENDER, OVER SHARING, AND CYBERBULLYING IN ONLINE MULTI-PLAYER GAMING (MMOG) ENVIRONMENTS
}

\author{
Meg Fryling, Siena College, mfryling@siena.edu
}

\begin{abstract}
Cyberbullying in online gaming environments has been researched in recent years and has been found to impact victims similarly to traditional bullying. The relationship between gender and cyberbullying activities, has also been investigated. While some studies have indicated that girls may be more likely to participate in some forms of cyberbullying behavior (e.g. posting, texting, and instant messaging hurtful things), many researchers have found that male gamers are more likely to be the perpetrators of cyberbullying during online gaming. This paper extends existing research by focusing on the relationship between player gender, avatar gender, personal data sharing, and cyberbullying behavior in Massively Multiplayer Online Gaming (MMOG) environments. While this research found that gamers perceive that there is a relationship between gender and the likelihood of cyberbullying behavior/victimization, players actually reporting that they have been the victim of cyberbullying is not vastly different between avatar genders nor real player genders. Of those that never exhibit cyberbullying behavior, most are female gender and almost half use a female avatar exclusively. In addition, there seemed to be an emerging theme that sharing personal data, in particular a real picture of oneself, may be related to cyberbullying in online gaming environments. Although both genders tended to share the same number of personal data items, female players were more likely to share a real picture of themselves.
\end{abstract}

Keywords: video games, online gaming, MMOG, cyberbullying, cyber-victimization, gender, avatar

\section{INTRODUCTION}

In recent years, researchers have studied cyberbullying in gaming environments (e.g. Ballard and Welch, 2015; Cotler, et al., 2017; Przybylski et al., 2014; Fryling et al., 2015; Varjas et al., 2013; Yang, 2012) and, like other types of bullying, it has been found to have a negative psychological impact its victims (Fryling, et al., 2015; Juvonen \& Gross, 2008; Kim, Koh, \& Leventhal, 2005; Klomek, Sourander, \& Gould, 2010; Mason, 2008; Mesch, 2009; Patchin \& Hinduja, 2007). Whether violence in video games is the culprit of violent, aggressive, and/or cyberbullying behavior is heavily investigated and passionately debated by researchers. While some research supports the belief that violence in video games increases hostile behavior (Anderson \& Bushman, 2001; Anderson et al., 2007; Anderson et al., 2010; Bushman \& Anderson, 2002; Hasan et al., 2013; Lam, et al, 2013; Power, 2009; Yang, 2012), other researchers report that there is no causal relationship between violent video games and violent behavior (Ferguson, 2010; Ferguson \& Kilburn, 2010; Przybylski et al., 2014; Sherry, 2007).

Other studies have concluded that player incompetence of the gaming environment triggers aggressive behavior from others and makes "newbie" players vulnerable to cyberbullying victimization (Przybylski et al., 2014). Cotler, et al. (2017), found that gamers perceived the biggest causes of cyberbullying in online gaming environments are anonymity, inability to see real-life impact on victims, and no fear of punishment. Other research in this domain has also identified sexual orientation and revenge as triggers of cyberbullying behavior (Varjas et al., 2013).

Ballard and Welch (2015) found that 52\% of Massively Multiplayer Online Gaming (MMOG) players reported being cyberbullied and 35\% admitted to participating in cyberbullying during MMOG play, with rank being the most frequent motive. Fryling, et al. (2015) cyberbullying victimization numbers were higher with $78 \%$ (79\% of females and $73 \%$ of males) of MMOG respondents reporting they have been cyberbullied in MMOG environments and $91 \%$ (same for males and females) stating they have been the witness of MMOG cyberbullying activities. However, Fryling et al. (2015) numbers were identical to Ballard and Welch (2015) for those acknowledging being a MMOG cyberbully (i.e. $35 \%$ ), with $29 \%$ of females and $42 \%$ of males admitting to cyberbullying others. Even more concerning is that victims and witnesses of cyberbullying may be more likely to become cyberbullies themselves, 
thus exasperating the problem (Berthold \& Hoover, 2000; Fryling \& Rivituso, 2013; Fryling et al., 2015; Katzer, 2009; Wong \& Xio, 2012; Yang, 2012; Ybarra \& Mitchell, 2004).

\section{Gender and Cyberbullying}

The relationship between gender and cyberbullying activities, has also been investigated. While traditional physical bullying is more prevalent among males, research of northeastern middle students found that cyberbullying is more prevalent among females (Connell, et al., 2014). Connell, et al. (2014) report that females were significantly more likely than males $(p<.01)$ to engaging in and be victimized by the following three modes of cyberbullying: (1) posting unkind or hurtful things on the Internet; (2) calling, texting, or e-mailing mean things; and (3) instant messaging unkind or hurtful things. Almeida et al. (2012) support these findings, reporting that regardless of age, girls were significantly more likely to report being a victim of cyberbullying than boys. Girls may be more subject to being a victim of cyberbullying because of their predisposition to cyberbully others (Navarro \& Jasinski, 2013).

However, in MMOG environments Ballard \& Welch (2015) reported that:

(a) males perpetrate more cyberbullying in MMOGs than females do; (b) heterosexuals perpetrate bullying at higher rates than lesbian, gay, bisexual, and transgender (LGBT) participants do; (c) female and LGBT participants experienced significantly higher rates of sexually related cyber-victimization; and (d) opponents are bullied more than teammates. Rates of victimization and perpetration overlapped substantially.

Fryling, et al. (2015) also found that males (42\%) were more likely to be a MMOG cyberbully than females (29\%). Yang (2012) also found that repetitive cyberbullying victimization of male online gamers increases the probability of them demonstrating aggressive behavior outside of the gaming environment. While Fryling, et al. (2015) reported that both male and female cyberbullying victims had increased offline aggression, with no major difference between the genders.

Not only is biological gender a potential impact in cyberbullying activities in MMOGs, but the gender of the game character (or avatar) may play a role as well. Female player self-efficacy can be damaged when their game play involves using a sexualized female avatar and may negatively influence the perceptions of women in the real world (Behm-Morawitz \& Mastro 2009). Behm-Morawitz \& Schipper (2016) studied the relationship between avatar gender in Second Life and cyberbullying and found that sexualization of female avatars was associated with cyberbullying. The purpose of this paper it to extend existing research by focusing on real player gender, avatar gender, and personal data sharing in MMOG environments and cyberbullying behavior.

\section{RESEARCH METHODOLOGY}

A survey regarding bullying in MMOG environments was developed and reviewed by four frequent MMOG gamers. Based on their feedback questions were added and minor modifications were made to make questions clearer, including appropriate gaming lingo. The survey was then posted, with permission, to an online gaming forum.

Data from 990 gamer respondents were analyzed, focusing on the following survey questions:

- What gender do you typically play as in multi-player video games?

- Based on your definition of cyberbullying, do you think male or female players are more likely to be the cyberbullier within multi-player video games?

- Based on your definition of cyberbullying, do you think male or female players are more likely to be the victim of cyberbullying within multi-player video games?

- How much personal information do you share in online gaming environments?

- What are the contributing factors to the cyberbullying activities in online gaming environments (i.e. Avatar Gender, Player Gender)? 
- Based on your definition of cyberbullying, please estimate how often you have experienced cyberbullying (as a victim, witness, and/or as the individual exhibiting the bullying behavior) within multi-player video games.

Our research centered upon the following research questions:

- Is there some relationship between real gender, avatar gender, and being a bully or experiencing cyberbullying?

- Is there a relationship between how much personal information you share, and if you experience cyberbullying?

\section{RESULTS}

Of the 990 respondents, 367 (37\%) were male, $605(61 \%)$ were female, and $18(2 \%)$ identified as a gender other than male or female. As for online gaming personas, $287(29 \%)$ respondents reported they use male avatars exclusively, 431 (43\%) use female avatars exclusively, 245 (25\%) use both male and female avatars, and $16(3 \%)$ use genderless/other avatars. $58 \%$ of respondents have witnessed player gender contributing to bullying and $29 \%$ witnessed avatar gender contributing to bullying. When we asked respondents which gender was most likely to be a cyberbully, a majority reported males. $27 \%$ of respondents believe that female players are more likely to the victim of cyberbullying in online gaming environments, while only $10 \%$ believe male players are more likely to be a victim. However, $63 \%$ of respondents felt both males and females were equally likely to be a victim of bullying (see Table 1).

Table 1. Gender Most Likely to Be Bully and/or Victim

\begin{tabular}{|l|l|l|l|}
\hline & Male & Female & Both Equally Likely \\
\hline Gender Most Likely to be Victim & $10 \%$ & $27 \%$ & $63 \%$ \\
\hline Gender Most Likely to be Bully & $58 \%$ & $1 \%$ & $41 \%$ \\
\hline
\end{tabular}

The data were then loaded to Weka for additional analysis. Weka is a collection of machine learning algorithms for data mining tasks. The algorithms can either be applied directly to a dataset or called from your own Java code. Weka contains tools for data pre-processing, classification, regression, clustering, association rules, and visualization (WEKA 2018). The following subsections will describe the data analysis and findings.

\section{Expectation Maximization (EM) Clustering Algorithm}

The first Weka analysis performed used the Expectation Maximization (EM) clustering algorithm to partition data sets into groups. EM assigns a probability distribution to each instance which indicates the probability of it belonging to each of the clusters. The EM cluster algorithm was run on the dataset for the "Victim of Cyberbullying" class. The results produced three clusters (see Table 2). 
Issues in Information Systems

Volume 19, Issue 2, pp. 140-148, 2018

Table 2. EM Clustering on Victim of Cyberbullying

\begin{tabular}{|c|c|c|c|}
\hline & Cluster 1 (18\%) & Cluster $2(54 \%)$ & Cluster 3 (28\%) \\
\hline Age Mean & 25 & 22 & 19 \\
\hline $\begin{array}{c}\text { Gender \% of Total Respondents in } \\
\text { Cluster }\end{array}$ & $\begin{array}{l}25 \% \text { Male } \\
22 \% \text { Female }\end{array}$ & $\begin{array}{l}38 \% \text { Male } \\
49 \% \text { Female }\end{array}$ & $\begin{array}{l}37 \% \text { Male } \\
29 \% \text { Female }\end{array}$ \\
\hline Avatar Gender Typically Play & $\begin{array}{c}30 \% \text { Male } \\
42 \% \text { Female } \\
24 \% \text { Both } \\
4 \% \\
\text { Genderless/Other }\end{array}$ & $\begin{array}{c}27 \% \text { Male } \\
51 \% \text { Female } \\
20 \% \text { Both } \\
2 \% \\
\text { Genderless/Other }\end{array}$ & $\begin{array}{c}30 \% \text { Male } \\
33 \% \text { Female } \\
32 \% \text { Both } \\
5 \% \\
\text { Genderless/Other }\end{array}$ \\
\hline Mean Share Level ${ }^{1}$ & 0.7382 & 4.9593 & 6.8615 \\
\hline Victim of Cyberbullying & Never & Rarely & Sometimes \\
\hline
\end{tabular}

This analysis clustered the respondents into 3 groups (see Clusters 1-3 in Table 2). The first group (18\% of respondents) were grouped as never having been the victim of cyberbullying in gaming environments, the second group (54\% of respondents) rarely a victim, and the third group (28\% of respondents) sometimes victims. Approximately half of the female respondents clustered by this analysis are in Cluster 2, which are rarely the victim of cyberbullying. The other half are fairly evenly distributed between never the victim of cyberbullying and sometimes the victim of cyberbullying. As for avatar gender, the Clusters $1 \& 2$ have the most individuals that use a female avatar exclusively. These clusters are the individuals that are never or rarely cyberbullied.

While the results of this analysis do not reveal a clear player/avatar gender and cyberbullying correlation, it does indicate that there may be a relationship between how much personal information a player shares and the likelihood they will be the victim of cyberbullying in gaming environments. The cluster experiencing the most cyberbullying victimization (Cluster 3) has the highest mean share level. This number was determined by evaluating how many personal items the player reported they share in online gaming environments, such as age, gender, etc. Table 3 shows all the reported personal data items and percentages of all respondents that share these items, by gender.

Table 3. Percentage of Respondents Sharing Personal Data in Gaming Environments

\begin{tabular}{|l|l|l|}
\hline Personal Data Item & $\begin{array}{l}\text { Percentage of } \\
\text { Males that Share }\end{array}$ & $\begin{array}{l}\text { Percentage of } \\
\text { Females that Share }\end{array}$ \\
\hline Race/Ethnicity & $14 \%$ & $15 \%$ \\
\hline Religion & $5 \%$ & $4 \%$ \\
\hline First Name & $55 \%$ & $61 \%$ \\
\hline Last Name & $11 \%$ & $7 \%$ \\
\hline Gender & $69 \%$ & $74 \%$ \\
\hline Age & $49 \%$ & $47 \%$ \\
\hline National Origin & $32 \%$ & $26 \%$ \\
\hline Marital Status & $5 \%$ & $9 \%$ \\
\hline Level of Gaming Experience & $42 \%$ & $29 \%$ \\
\hline How long playing the game & $46 \%$ & $40 \%$ \\
\hline Where you live & $26 \%$ & $31 \%$ \\
\hline Number of video game misdemeanors you have & $3 \%$ & $2 \%$ \\
\hline Picture of your avatar & $67 \%$ & $69 \%$ \\
\hline Picture of you & $8 \%$ & $13 \%$ \\
\hline Your friend list & $35 \%$ & $24 \%$ \\
\hline
\end{tabular}

\footnotetext{
${ }^{1}$ On a scale of $0-15$ of how much personal information (e.g. Age, Gender, Real Name) they share in the gaming environment.
} 
As shown in Table 3, many of the percentages are very similar between the genders. However, female respondents are more likely to share their first name, gender, where they live, and a picture of themselves. While male respondents are quite a bit more likely to share level of gaming experience, how long they have played the game, and their friend list.

While the EM analysis gives some indication that individuals that share more personal information are more likely to be the victim of cyberbullying, the algorithm only successfully clustered approximately $40 \%$ of the respondent data. That means that $60 \%$ of the respondent data was placed in a cluster that did not accurately reflect the level to which they had been the victim of cyberbullying in online gaming environments. As such, further examination of the data is necessary.

The EM Cluster was then run for the same dataset but on the "Exhibiting Cyberbullying Behavior" class. The results produced four clusters (see Table 4). The first group (43\% of respondents) were grouped as never having exhibited cyberbullying behavior in gaming environments, the second group ( $16 \%$ of respondents) rarely exhibit cyberbullying behavior, the third group (23\% of respondents) sometimes exhibit cyberbullying behavior, and the fourth group (18\% of respondents) often exhibit cyberbullying behavior. A potentially interesting observation is that the individuals most likely to exhibit cyberbullying behavior (Cluster 4), are much less likely to share personal information about themselves in the gaming environment. In addition, while most of the individuals in Cluster 4 are males, $70 \%$ of the players in this cluster use female avatars exclusively, both male and female avatars, or genderless/other avatars.

Table 4. EM Clustering on Exhibiting Cyberbullying Behavior

\begin{tabular}{|c|c|c|c|c|}
\hline & Cluster 1 (43\%) & Cluster 2 (16\%) & Cluster 3 (23\%) & Cluster 4 (18\%) \\
\hline Age Mean & 23 & 19 & 20 & 25 \\
\hline $\begin{array}{c}\text { Gender \% of Total } \\
\text { Respondents in Cluster }\end{array}$ & $\begin{array}{c}30 \% \text { Male } \\
37 \% \text { Female }\end{array}$ & $\begin{array}{c}30 \% \text { Male } \\
12 \% \text { Female }\end{array}$ & $\begin{array}{c}18 \% \text { Male } \\
31 \% \text { Female }\end{array}$ & $\begin{array}{c}22 \% \text { Male } \\
20 \% \text { Female }\end{array}$ \\
\hline $\begin{array}{c}\text { Avatar Gender Typically } \\
\text { Play }\end{array}$ & $\begin{array}{c}28 \% \text { Male } \\
50 \% \text { Female } \\
19 \% \text { Both } \\
3 \%\end{array}$ & $\begin{array}{c}41 \% \text { Male } \\
32 \% \text { Female } \\
3 \%\end{array}$ & $\begin{array}{c}3 \% \text { Male } \\
48 \% \text { Female } \\
29 \% \text { Both } \\
4 \%\end{array}$ & $\begin{array}{c}30 \% \text { Male } \\
43 \% \text { Female } \\
22 \% \text { Both } \\
5 \%\end{array}$ \\
$\begin{array}{c}\text { Genderless/Other } \\
\text { Genderless/Other }\end{array}$ & $\begin{array}{c}\text { Genderless/Other } \\
\text { Genderless/Other }\end{array}$ \\
\hline $\begin{array}{c}\text { Mean Share Level } \\
\text { Exhibiting Cyberbullying } \\
\text { Behavior }\end{array}$ & Never & Rarely & Sometimes & 0.5441 \\
\hline
\end{tabular}

While this EM run (Table 4) performed slightly better than the previous run (Table 3 ), correctly clustering $57 \%$ of the instances, additional analysis is warranted.

\section{Naïve Bayes Classifying Algorithm}

In an effort to get a more accurate analysis of the dataset, a Naïve Bayes Classifying Algorithm analysis was run in Weka. This analysis was able to correctly classify $98.7879 \%$ of the instances into 5 groups (see Clusters $1-5$ in Table 5). The first group ( $22 \%$ of classified respondents) have never been the victim of cyberbullying in gaming environments, the second group (38\% of classified respondents) rarely are victims, the third group (30\% of respondents) are sometimes victims, the fourth ( $8 \%$ of classified respondents) often are victims, and the fifth $(2 \%$ of respondents) are victims all of the time.

\footnotetext{
${ }^{2}$ On a scale of $0-15$ of how much personal information (e.g. Age, Gender, Real Name) they share in the gaming environment.
} 


\section{Issues in Information Systems}

Volume 19, Issue 2, pp. 140-148, 2018

Table 5. Naive Bayes Classification on Victim of Cyberbullying Class ${ }^{3}$

\begin{tabular}{|c|c|c|c|c|c|}
\hline & Cluster $1(22 \%)$ & Cluster $2(38 \%)$ & Cluster $3(30 \%)$ & Cluster $4(8 \%)$ & Cluster $5(2 \%)$ \\
\hline Age Mean & 23 & 22 & 22 & 22 & 19 \\
\hline $\begin{array}{c}\text { Gender \% of } \\
\text { Total } \\
\text { Respondents }\end{array}$ & $\begin{array}{c}26 \% \text { Male } \\
20 \% \text { Female }\end{array}$ & $\begin{array}{c}38 \% \text { Male } \\
38 \% \text { Female }\end{array}$ & $\begin{array}{c}30 \% \text { Male } \\
30 \% \text { Female }\end{array}$ & $\begin{array}{l}<5 \% \text { Male } \\
9 \% \text { Female }\end{array}$ & $\begin{array}{l}<2 \% \text { Male } \\
3 \% \text { Female }\end{array}$ \\
\hline $\begin{array}{l}\text { Avatar Gender } \\
\text { Typically Play }\end{array}$ & $\begin{array}{c}30 \% \text { Male } \\
41 \% \text { Female } \\
25 \% \text { Both } \\
4 \% \\
\text { Genderless/Other }\end{array}$ & $\begin{array}{c}32 \% \text { Male } \\
42 \% \text { Female } \\
24 \% \text { Both } \\
2 \% \\
\text { Genderless/Other }\end{array}$ & $\begin{array}{c}27 \% \text { Male } \\
45 \% \text { Female } \\
24 \% \text { Both } \\
4 \% \\
\text { Genderless/Other }\end{array}$ & $\begin{array}{c}18 \% \text { Male } \\
\text { 48\% Female } \\
26 \% \text { Both } \\
8 \% \\
\text { Genderless/Other }\end{array}$ & $\begin{array}{c}20 \% \text { Male } \\
38 \% \text { Female } \\
28 \% \text { Both } \\
14 \% \\
\text { Genderless/Other }\end{array}$ \\
\hline $\begin{array}{c}\text { Share Real } \\
\text { Picture of } \\
\text { Themselves }\end{array}$ & $8 \%$ & $11 \%$ & $14 \%$ & $15 \%$ & $20 \%$ \\
\hline $\begin{array}{c}\text { Mean Share } \\
\text { Level }\end{array}$ & 3.9358 & 4.6197 & 4.8983 & 5.1667 & 4.3478 \\
\hline $\begin{array}{c}\text { Victim of } \\
\text { Cyberbullying }\end{array}$ & Never & Rarely & Sometimes & Often & All of the Time \\
\hline
\end{tabular}

Again, this analysis indicates no strong correlation between player/avatar gender and cyberbullying victimization. However, as with the EM analysis, it does lend some support to the idea that sharing personal information and cyberbullying victimization are related. Clusters 1-4 show both an increase in Mean Share Level and an increase in cyberbullying victimization. The one anomaly is Cluster 5 but it should be noted that this cluster contains only $2 \%$ of the respondents. A new discovery from this analysis was that the percentage of individuals specifically sharing a real picture of themselves steadily increased from the Never a victim of cyberbullying ( $8 \%$ share picture) in Cluster 1 to a victim of cyberbullying All of the Time (20\% share picture) in Cluster 5.

The Naïve Bayes Classifying Algorithm analysis was then run on the "Exhibiting Cyberbullying Behavior" class. This analysis was able to correctly classify $98.2828 \%$ of the instances into 5 groups (see Table 6). The first group (65\% of respondents) were grouped as never having exhibited cyberbullying behavior in gaming environments, the second group (26\% of respondents) rarely exhibit cyberbullying behavior, the third group ( $7 \%$ of respondents) sometimes exhibit cyberbullying behavior, the fourth group (2\%) often exhibit cyberbullying behavior, and the fifth group ( $1 \%$ of respondents) exhibit cyberbullying behavior all of the time.

\footnotetext{
${ }^{3}$ Testing option: Cross-validation 10 -fold
} 
Issues in Information Systems

Volume 19, Issue 2, pp. 140-148, 2018

Table 6. Naive Bayes Classification on Exhibiting Cyberbullying Behavior Class ${ }^{4}$

\begin{tabular}{|c|c|c|c|c|c|}
\hline & Cluster $1(65 \%)$ & Cluster $2(26 \%)$ & Cluster 3 (7\%) & Cluster 4 (2\%) & Cluster 5 (1\%) \\
\hline Age Mean & 23 & 21 & 21 & 20 & 20 \\
\hline $\begin{array}{l}\text { Gender \% of } \\
\text { Total } \\
\text { Respondents }\end{array}$ & $\begin{array}{l}57 \% \text { Male } \\
70 \% \text { Female }\end{array}$ & $\begin{array}{c}30 \% \text { Male } \\
22 \% \text { Female }\end{array}$ & $\begin{array}{l}9 \% \text { Male } \\
6 \% \text { Female }\end{array}$ & $\begin{array}{c}3 \% \text { Male } \\
<2 \% \text { Female }\end{array}$ & $\begin{array}{c}1 \% \text { Male } \\
<1 \% \text { Female }\end{array}$ \\
\hline $\begin{array}{l}\text { Avatar Gender } \\
\text { Typically Play }\end{array}$ & $\begin{array}{c}26 \% \text { Male } \\
48 \% \text { Female } \\
23 \% \text { Both } \\
3 \% \\
\text { Genderless/Other }\end{array}$ & $\begin{array}{c}34 \% \text { Male } \\
36 \% \text { Female } \\
26 \% \text { Both } \\
4 \% \\
\text { Genderless/Other }\end{array}$ & $\begin{array}{c}38 \% \text { Male } \\
26 \% \text { Female } \\
30 \% \text { Both } \\
6 \% \\
\text { Genderless/Other }\end{array}$ & $\begin{array}{c}19 \% \text { Male } \\
27 \% \text { Female } \\
35 \% \text { Both } \\
19 \% \\
\text { Genderless/Other }\end{array}$ & $\begin{array}{c}21 \% \text { Male } \\
29 \% \text { Female } \\
29 \% \text { Both } \\
21 \% \\
\text { Genderless/Other }\end{array}$ \\
\hline $\begin{array}{l}\text { Share Real } \\
\text { Picture of } \\
\text { Themselves }\end{array}$ & $9 \%$ & $18 \%$ & $16 \%$ & $18 \%$ & $20 \%$ \\
\hline $\begin{array}{c}\text { Mean Share } \\
\text { Level }\end{array}$ & 4.3302 & 5.332 & 4.6418 & 3.4 & 4.375 \\
\hline $\begin{array}{c}\text { Exhibited } \\
\text { Cyberbullying } \\
\text { Behavior }\end{array}$ & Never & Rarely & Sometimes & Often & All of the Time \\
\hline
\end{tabular}

This analysis seems to indicate that female players are less likely to exhibit cyberbullying behavior, with $70 \%$ of female players never having exhibited cyberbullying behavior in online gaming environments, versus only $57 \%$ of male players. This group (Cluster 1) is also more likely than other groups to exclusively use a female avatar. There is no clear pattern between level of cyberbullying behavior exhibited and mean share level. However, similarly to the cyberbullying victimization, those that never exhibit cyberbullying behavior (Cluster 1) are quite a bit less likely to share a real picture of themselves than any of the other groups. Finally, it is important to note that those most likely to exhibit cyberbullying behavior (Clusters $4 \& 5$ ) had a much higher number of individuals using avatars that are neither male or female (i.e. genderless/other).

\section{SUMMARY}

Overall online gamers report that male players are more likely to be bullies and female players are somewhat more likely to be the victim of cyberbullying in online gaming environments. Although only about $1 / 4$ of the respondents have witnessed avatar gender contributing to cyberbullying behavior, a majority state that they have witnessed real player gender contributing to cyberbullying behavior. None of the additional Weka data analysis performed in this research indicated that avatar gender contributes to cyberbullying victimization in online gaming environments. Though it did show that those that never exhibit cyberbullying behavior tend to use female avatars more exclusively than other groups. Additionally, while our respondents perceive that there is some relationship between real gender and cyberbullying victimization, the additional Weka data analysis in this study did not heavily support that perception. However, it did lend some support to the theory that female players are less likely to exhibit cyberbullying behavior in gaming environments.

The clustering and classifying algorithms run in Weka did suggest that there may be some correlation between increased sharing of personal information and the likelihood that one will become a victim of cyberbullying. Still,

\footnotetext{
${ }^{4}$ Testing option: Cross-validation 10 -fold
} 
there was one cluster anomaly that did not fully support this theory. Nonetheless, both the Weka EM clustering and Naïve Bayes classifying analysis did reveal a possible relationship between specifically sharing a real picture of the player and cyberbullying in online gaming environments. Looking back at the gender angle, more female players reported sharing a real picture of themselves (13\% share picture) than male players ( $8 \%$ share picture) so further investigation is necessary into the relationship between real gender, personal information sharing, and cyberbullying in online gaming environments. Nonetheless, it may be advisable to limit the sharing of personal information, including gender and profile pictures with a player's real image.

\section{REFERENCES}

Almeida, A. , Correia, I. , Marinho, S. \& Garcia, D. (2012). Virtual but not Less Real. In: Q. Li, D. Cross and P. K. Smith (Eds.) Cyberbullying in the Global Playground. Research from International Perspectives. Blackwell Publishing Ltd. doi:10.1002/9781119954484.ch11.

Anderson, C. A., \& Bushman, B. J. (2001). Effects of Violent Video Games of Aggressive Behavior, Aggressive Cognition, Aggressive Affect, Physiological Arousal, and Prosocial Behavior: A Meta-Analytic Review of the Scientific Literature. Psychological Science, 12, 353-359.

Anderson, C. A., Gentile, D. A., \& Buckley, K. E. (2007). Violent video game effects on children and adolescents: Theory, research, and public policy. New York, NY: Oxford University Press.

Anderson, C. A., Shibuya, A., Ihori, N., Swing, E. L., Bushman, B. J., Sakamoto, A., \& Saleem, M. (2010). Violent video game effects on aggression, empathy, and prosocial behavior in Eastern and Western countries. Psychological Bulletin, 136, 151-173.

Ballard, M.E. \& Welch, K.M. (2015). Virtual warfare: Cyberbullying and cyber-victimization in MMOG play. Games and Culture, 12(5), 466-491.

Behm-Morawitz, E., \& Mastro, D. (2009). The effects of the sexualization of female video game characters on gender stereotyping and female self-concept. Sex Roles, 61, 808-823.

Behm-Morawitz, E., \& Schipper, S. (2016). Sexing the avatar: Gender, sexualization, and cyber-harassment in a virtual world. Journal of Media Psychology: Theories, Methods, and Applications, 28(4), 161-174.

Bushman, B. J., \& Anderson, C. A. (2002). Violent Video Games and Hostile Expectations: A Test of the General Aggression Model. Personality \& Social Psychology Bulletin, 28, 1679-1686.

Connell, N.M., Schell-Busey, N.M., Pearce, A.N. \& Negro, P. (2014) Badgrlz? Exploring sex differences in cyberbullying behaviors. Youth Violence and Juvenile Justice, 12(3), 209-228.

Cotler, J. L., Fryling, M., Rivituso, J. (2017). Causes of cyberbullying in multi-player online gaming environments: Gamer perceptions. Journal of Information Systems Applied Research, 10(1), 4-14. http://jisar.org/2017-10/ ISSN: 1946-1836. (A preliminary version appears in The Proceedings of CONISAR 2016)

Ferguson, C. J. (2010). Blazing angels or resident evil? Can violent video games be a force for good? Review of General Psychology, 14(2), 68-81.

Ferguson, C. J., \& Kilburn, J. (2010). Much ado about nothing: The misestimation and overinterpretation of violent video game effects in Eastern and Western nations: Comment on Anderson et al. (2010). Psychological Bulletin, 136(2), 174-178.

Fryling, M., Cotler, J. L., Rivituso, J., Mathews, L., \& Pratico, S. (2015). Cyberbullying or normal game play? Impact of age, gender, and experience on cyberbullying in multi-player online gaming environments: Perceptions from one gaming forum. Journal of Information Systems Applied Research, 8(1), 4-18. 
http://jisar.org/2015-8/ ISSN: 1946-1836. (A preliminary version appears in The Proceedings of CONISAR 2014).

Hasan, Y., Bègue, L., Scharkow, M., \& Bushman, B. J. (2013). The more you play, the more aggressive you become: A long-term experimental study of cumulative violent video game effects on hostile expectations and aggressive behavior. Journal of Experimental Social Psychology, 49(2), 224-227.

Jordana N. Navarro \& Jasinski, J. L. (2013) Why Girls? Using Routine Activities Theory to Predict Cyberbullying Experiences Between Girls and Boys, Women \& Criminal Justice, 23(4), 286-303,

Juvonen, J., \& Gross, E. (2008). Extending the School Grounds? - Bullying Experiences in Cyberspace. Journal of School Health, 78, 496-505.

Kim, Y., Koh, Y., \& Leventhal, B. (2005). School Bullying and Suicidal Risk among Korean Middle School Students. Pediatrics: The Official Journal of the American Academy of Pediatrics, 115, 357-363.

Klomek, A., Sourander, A., \& Gould, M. (2010). The Association of Suicide and Bullying in Childhood to Young Adulthood: A Review of Cross-Sectional and Longitudinal Research Findings. The Canadian Journal of Psychiatry, 55, 282-288.

Lam, L., Cheng, Z., \& Liu, X. (2013). Violent Online Games Exposure and Cyberbullying/Victimization Among Adolescents. CyberPsychology, Behavior \& Social Networking, 16(3), 159-165.

Mason, K. (2008). Cyberbullying: A Preliminary Assessment for School Personnel. Psychology in the Schools, 45, 323-348.

Mesch, G. (2009). Parental Mediation, Online Activities, and Cyberbullying. CyberPsychology \& Behavior, 12, $387-393$.

Patchin, J., \& Hinduja, S. (2007). Offline Consequences of Online Victimization: School Violence and Delinquency. Journal of School Violence, 6, 89-112.

Power, M. R. (2009). Video Games and a culture of conflict. Journal of Children and Media, 3, 90-94.

Przybylski, A. K., Deci, E. L., Rigby, C. S., \& Ryan, R. M. (2014). Competence-Impeding Electronic Games and Players' Aggressive Feelings, Thoughts, and Behavior. Journal of Personality and Social Psychology, 106(3), 441-457.

Qing L (2015) When Cyberbullying and Bullying Meet Gaming: A systemic Review of the Literature. Journal of Psychology \& Psychotherapy, 5(195). doi:10.4172/2161-0487.1000195.

Sherry, J. L. (2007). Violent video games and aggression: Why can't we find effects? In R. W. Preiss, B. M. Gayle, N. Burrell, M. Allen, \& J. Bryant (Eds.), Mass media effects research: Advances through meta-analysis (Vol. xii, pp. 245-262). Mahwah, NJ, US: Lawrence Erlbaum Associates Publishers.

Varjas, K., Meyers, J., Kiperman, S., \& Howard, A. (2013). Technology Hurts? Lesbian, Gay, and Bisexual Youth Perspectives of Technology and Cyberbullying. Journal of School Violence, 12(1), 27-44.

WEKA (2018). Weka 3: Data Mining Software in Java; https://www.cs.waikato.ac.nz/ml/weka/

Yang, S. C. (2012). Paths to Bullying in Online Gaming: The Effects of Gender, Preference for Playing Violent Games, Hostility, and Aggressive Behavior on Bullying. Journal of Educational Computing Research, $47(3), 235$ - 249. 